\title{
COMPARING FOOT ANESTHESIA ACHIEVED USING TWO INJECTION SITES IN THE ANKLE IN PATIENTS UNDERGOING FOOT SURGERY
}

\section{Information sheet for research subjects}

The objective of the present trial is to compare the anesthetic efficiency of two posterior tibial nerve blocking methods: the supramalleolar technique and the retromalleolar technique. The aim is to measure the success rate of each of the two techniques, the surface area anesthetized, and the duration of the anesthetic effect of each of these techniques. Another key aim is to discover the patient's level of comfort during the anesthetic injection, both in the supramalleolar technique and in the retromalleolar technique. The ultimate purpose is to improve the quality of healthcare in foot anesthesia procedures.

To take part in this trial, you need to sign a form giving your informed consent to receiving local/regional anesthesia. Participation in this trial does not entail any additional consequences compared to other foot anesthesia techniques. No additional consequences means that you will still need to fast before surgery, intraoperational checks will be needed on your response to the drugs used and on your vital signs and you will need to be monitored during the postoperative period. The risks of the two anesthetic techniques being studied are the same as for other foot anesthesia techniques and are very infrequent in all cases. The most frequent complications, although rare, are temporary alterations in sensitivity owing to nerve damage following the injection. The benefits of these two anesthetic techniques are a smaller number of injections and a greater clinical safety margin because lower doses of local anesthetic are required.

Your participation in this trial is voluntary: you can decide not to take part and can withdraw your consent at any moment without altering your relationship with your podiatrist or affecting your treatment in any way.

The trial is taking place at the Podiatric Clinic of the University of Valencia and is not funded by any laboratory. The persons who are eligible to take part are patients of this foot clinic who will be undergoing surgery and who meet a number of conditions for inclusion. There is no payment for taking part.

If you have any questions please phone this number: XXXXXXX.

\section{Confidentiality agreement}

The principal researcher in this trial, María Benimeli-Fenollar, and the Podiatric Clinic of the University of Valencia will take appropriate measures to ensure the confidentiality of information on the health of the research subjects in accordance with the Spanish Personal Data Protection Act (Ley De Protección de Datos de carácter personal -LOPD- 15/1999 of December 13, 1999). You, the research subject, will allow the principal researcher to access information on you generated during this trial, for teaching and research purposes. 